\title{
DAMAGED PLASTICITY MODELLING OF CONCRETE IN FINITE ELEMENT ANALYSIS OF REINFORCED CONCRETE SLABS
}

\author{
AIKATERINI S. GENIKOMSOU ${ }^{*}$ AND MARIA A. POLAK ${ }^{\dagger}$ \\ University of Waterloo \\ Waterloo, ON CANADA \\ e-mail: agenikom@uwaterloo.ca \\ ${ }^{\dagger}$ University of Waterloo \\ Waterloo, ON CANADA \\ e-mail:polak@uwaterloo.ca
}

Key words: Concrete Damaged Plasticity model, Finite Element Analysis, Punching shear, Concrete slabs

\begin{abstract}
Two interior slab-column connections, previously tested, are analysed using 3D nonlinear finite element methods. These slabs were tested under vertical monotonically increasing imposed displacement through the column till failure. One slab specimen was without shear reinforcement that failed in punching shear, while the other slab had punching shear reinforcement and failed in flexure. Both specimens are analysed using the concrete damaged plasticity model offered in ABAQUS. Concrete damaged plasticity model is employed with the fictitious crack model based on the fracture energy; where different failure mechanisms are predicted for tension and compression. Damage can be introduced in the model and it is defined separate in compression and tension. The model can be also equipped with viscoplastic regularization that provides additional ductility in the structure and helps to overcome convergence problems that have been created by cracking and strain localization that relies on the smeared crack approach. Parametric investigation based on the material and plasticity parameters is performed for the specimen without shear reinforcement. All numerical results are compared to the test results in terms of loaddeflection responses and crack patterns. Finite element analysis results are in good agreement with the experimental results and can give an insight into the failure mechanisms and crack developments of each slab. The predictive capability of the calibrated models confirms their ability for parametric studies examining the punching shear behaviour of reinforced concrete slabs with and without shear reinforcement.
\end{abstract}

\section{INTRODUCTION}

Punching shear is caused by a transfer mechanism of shear forces from the slab to the connection and occurs within the discontinuity D-region, where the 3D state of stresses is complex. When the shear stresses exceed the slab's shear capacity, punching occurs. An inclined crack forms around the column and the punching shear cone appears, where the column separates from the slab.

Finite Element Analysis (FEA) of reinforced concrete slabs can give an insight into the slabs' behaviour by predicting the possible failure modes, supporting the 
experimental conclusions and finally extending these conclusions where the test measurements are not known. Many researchers have conducted FEA of reinforced concrete slabs [1,2]; however, FEA of shear reinforced slabs is limited due to the complexity of modelling the punching shear reinforcement.

In this paper, two reinforced concrete slabs, one without and the other with shear reinforcement, are analyzed using the ABAQUS FEA software [3]. The concrete is modelled with the concrete damaged plasticity model.

\section{TEST SPECIMENS}

Two interior reinforced concrete slabcolumn connections that were previously tested by Adetifa and Polak (2005) [4] are analyzed. Both slabs were tested under static loading through the column stub. The dimensions of the slabs in plan are $1800 \times 1800$ $\mathrm{mm}$ with simple supports at $1500 \times 1500 \mathrm{~mm}$. The dimensions of the columns are $150 \times 150$ $\mathrm{mm}$ and are extended $150 \mathrm{~mm}$ from the top and the bottom faces of the slabs. The thickness of the slabs is $120 \mathrm{~mm}$ and the effective depth is equal to $90 \mathrm{~mm}$. The dimensions of the slabs and the loading process are presented in Figure 1. The flexural reinforcement consists of $10 \mathrm{M}$ bars that are placed at distance $100 \mathrm{~mm}$ in tension side and $200 \mathrm{~mm}$ in compression side. Slab SB1 has no shear reinforcement, while SB4 is retrofitted with four rows of shear bolts (see Figure 1). The material properties of concrete and reinforcement are shown in Table 1 and Table 2 , respectively. Table 3 presents the test results. Specimen SB1 failed in punching shear at a load of $253 \mathrm{kN}$, while slab SB4 failed in flexure at a load of $360 \mathrm{kN}$. Figure 2 shows the test results for both slabs in terms of load-deflection, while Figures 3 and 4 present the crack pattern at failure of slab SB1 and SB4, respectively.

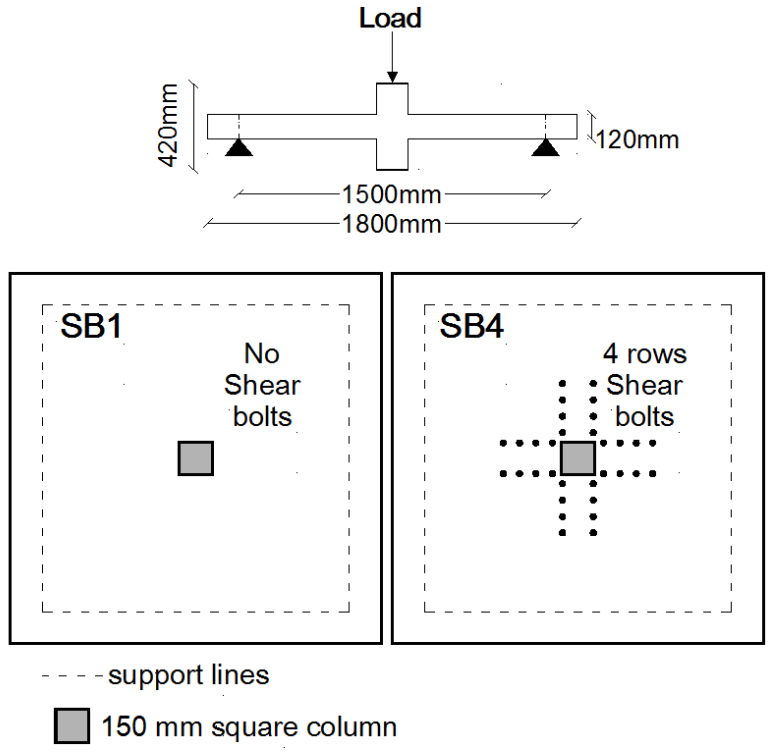

Figure 1: Schematic drawing of the slabs.

Table 1: Material properties of concrete of the slabs

\begin{tabular}{ccccc}
\hline Slab & $\begin{array}{c}\mathrm{f}_{\mathrm{c}}^{\prime} \\
(\mathrm{MPa})\end{array}$ & $\begin{array}{c}\mathrm{f}_{\mathrm{t}} \\
(\mathrm{MPa})\end{array}$ & $\begin{array}{c}\mathrm{G}_{\mathrm{f}}{ }^{*} \\
(\mathrm{~N} / \mathrm{mm})\end{array}$ & $\begin{array}{c}\mathrm{E}_{\mathrm{c}} \\
(\mathrm{MPa})\end{array}$ \\
\hline SB1 & 44 & 2.2 & 0.082 & 36483 \\
\hline SB4 & 41 & 2.1 & 0.077 & 35217 \\
\hline *Based on the CEB-FIP Model Code 1990
\end{tabular}

Table 2: Material properties of steel of the slabs

\begin{tabular}{ccccc}
\hline Slab & $\begin{array}{c}\mathrm{f}_{\mathrm{y}} \\
(\mathrm{MPa})\end{array}$ & $\begin{array}{c}\mathrm{f}_{\mathrm{t}} \\
(\mathrm{MPa})\end{array}$ & $\begin{array}{c}\mathrm{E}_{\mathrm{s}} \\
(\mathrm{MPa})\end{array}$ & $\begin{array}{c}\mathrm{f}_{\mathrm{y}, \text { bolts }} \\
(\mathrm{MPa})\end{array}$ \\
\hline SB1 & 455 & 620 & 200000 & - \\
\hline SB4 & 455 & 620 & 200000 & 381 \\
\hline
\end{tabular}

Table 3: Test results

\begin{tabular}{ccccc}
\hline Slab & $\begin{array}{c}\text { No. of } \\
\text { rows of } \\
\text { bolts }\end{array}$ & $\begin{array}{c}\text { Failure } \\
\text { load } \\
(\mathrm{kN})\end{array}$ & $\begin{array}{c}\text { Failure } \\
\text { displacement } \\
(\mathrm{mm})\end{array}$ & $\begin{array}{c}\text { Failure } \\
\text { mode }\end{array}$ \\
\hline SB1 & 0 & 253 & 11.9 & Punching \\
\hline SB4 & 4 & 360 & 29.8 & Flexure \\
\hline
\end{tabular}




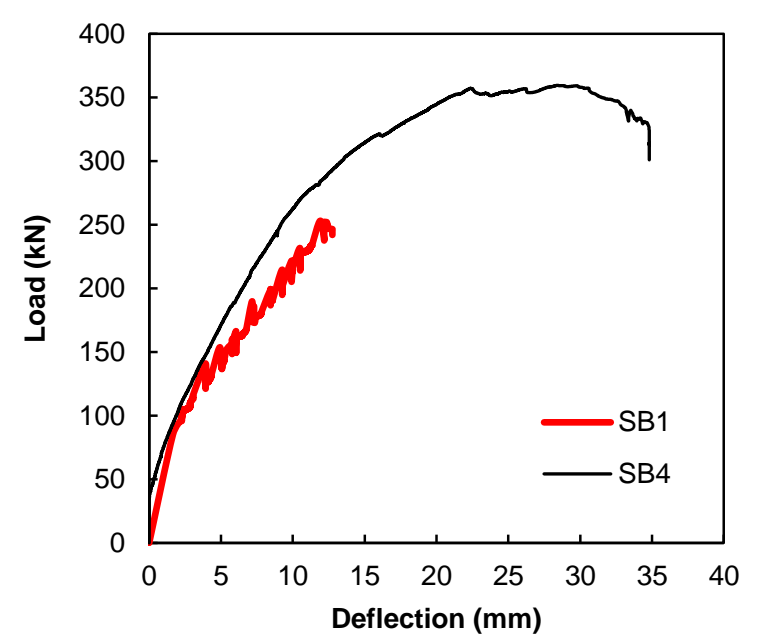

Figure 2: Load versus displacement (test results).

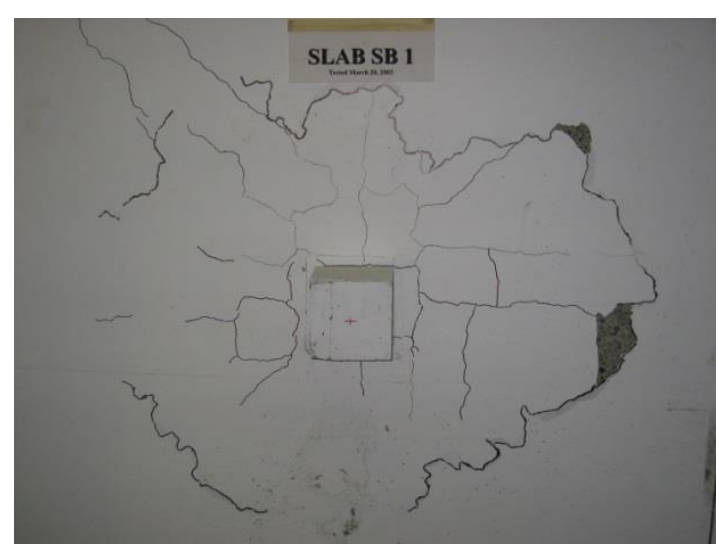

Figure 3: Crack pattern of slab SB1.

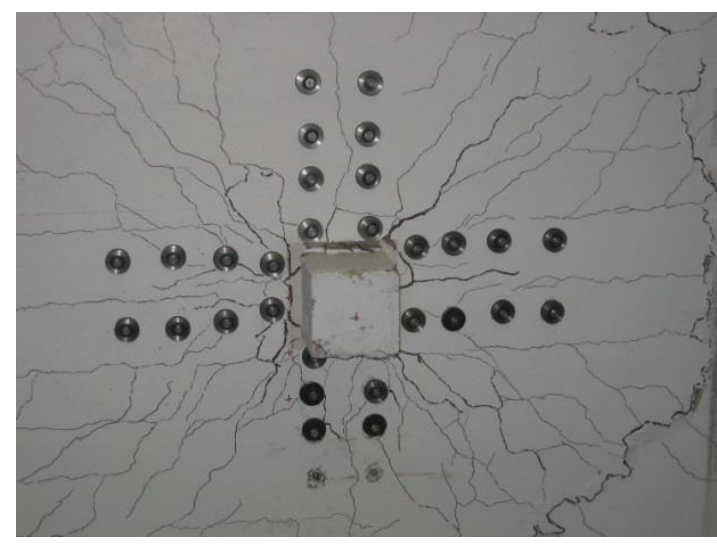

Figure 4: Crack pattern of slab SB4.

\section{FINITE ELEMENT MODELLING}

The FEA simulations are performed with the ABAQUS software. A short description of the concrete modelling is given and all the modelling assumptions are described below.

\subsection{Concrete Damaged Plasticity model}

The concrete damaged plasticity model considers both the tensile cracking and compressive crushing of concrete as possible failure modes [5]. The yield function of the concrete damaged plasticity model considers the effective stress space, where the effective stress is defined as: $\bar{\sigma}=\frac{\sigma}{(1-d)}=E_{o} \cdot(\varepsilon-$ $\tilde{\varepsilon}^{p l}$ ), where $E_{o}$ denotes the initial modulus of elasticity, $\tilde{\varepsilon}^{p l}$ is the equivalent plastic strain and $d$ is the damage variable that denotes the stiffness degradation.

Viscoplastic regularization according to the Duvaut-Lions approach can be defined in the concrete damaged plasticity model. By introducing the viscous parameter $(\mu)$ the plastic strain tensor is upgraded and the damage is deduced using additional relaxation time. The plastic potential function, that is employed in the model, is a non-associated Drucker-Prager hyperbolic function in which the definition of the dilation angle is needed.

For the visualization of cracking, concrete damaged plasticity model assumes that the cracking starts at points where the tensile equivalent plastic strain is bigger than zero and the maximum principal plastic strain is positive. The direction of the cracking is assumed to be parallel to the direction of the maximum principal plastic strain and it is viewed in the Visualization module of ABAQUS/CAE.

Concrete in tension can be characterized by a stress-crack displacement response instead of a stress-strain relationship due to its brittle behaviour. The stress-crack displacement relationship can be described with different options: linear, bilinear or exponential tension softening response (Figure 5).

The exponential stiffening curve can be calculated according to Cornelissen et al., 1986 [6] where the following equations should be considered:

$$
\begin{gathered}
\sigma / f_{t}^{\prime}=f(w)-\left(w / w_{c}\right) f\left(w_{c}\right) \\
f(w)=\left(1+\left(\frac{c_{1} w}{w_{c}}\right)^{3}\right) \exp \left(-\frac{c_{2} w}{w_{c}}\right)
\end{gathered}
$$




$$
w_{c}=5.14 \frac{G_{f}}{f_{t}^{\prime}}
$$

where $c_{1}$ and $c_{2}$ are material constants and can be considered equal to 3 and 6.93 for normal concrete, respectively.

The fracture energy of concrete $\left(G_{f}\right)$ represents the area under the tensile stresscrack displacement curve. The fracture energy is related to the concrete's strength and aggregate size and can be calculated using Eq. (2) (CEB-FIP Model Code 1990) [7].

$$
G_{f}=G_{f o}\left(f_{c m} / f_{c m o}\right)^{0.7}
$$

According to CEB-FIP Model Code 1990, $f_{c m o}=10 \mathrm{MPa}, f_{c m}$ is the mean value of the compressive strength associated with the characteristic compressive strength $\left(f_{c k}\right)$, $\left(f_{c m}=f_{c k}+8 \mathrm{MPa}\right)$ and $G_{f o}$ is the base fracture energy that depends on the maximum aggregate size, $d_{\max }$. The value of the base fracture energy $G_{f o}$ can be obtained from the CEB-FIP Model Code 90 and for example for an aggregate size $\left(d_{\max }\right)$ equal to $10 \mathrm{~mm}, G_{f o}$ is equal to $0.026 \mathrm{~N} / \mathrm{mm}$. In Table 1 the values of the fracture energies for both slabs are given. The new CEB-FIP Model Code 2010 [8] considers a different equation to calculate the fracture energy $\left(G_{f}=73 \cdot f_{c m}{ }^{0.18}\right)$. By using this formula the fracture energy for the slab specimen SB1 is equal to $0.148 \mathrm{~N} / \mathrm{mm}$ and the fracture energy for SB4 is equal to $0.146 \mathrm{~N} / \mathrm{mm}$

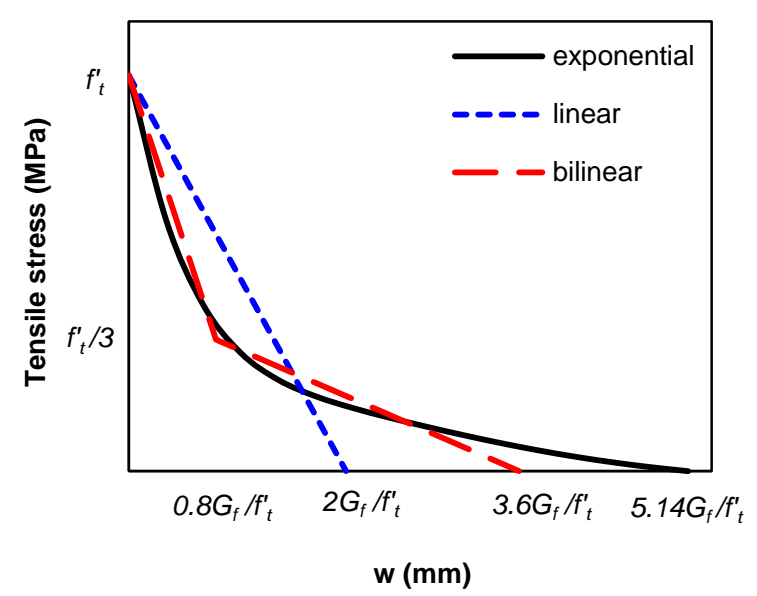

Figure 5: Stress-crack width curves in tension.

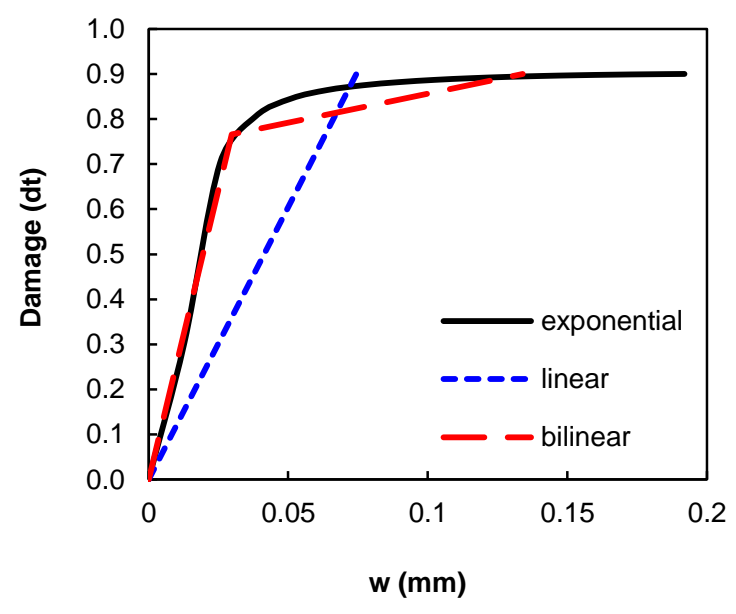

Figure 6: Tensile damage-crack width curves for slab

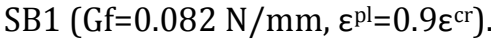

Figure 6 illustrates the tensile damage $\left(d_{t}\right)$ versus the crack displacement for the slab SB1. Concrete in compression is modelled with the Hognestad parabola. Figure 7 shows the stress-strain relationship for the slab SB1, where the stress-inelastic strain relationship and the stress-plastic strain relationship are shown. Figure 8 illustrates the compressive damage parameter $\left(d_{c}\right)$ versus the plastic strain curves for the slab SB1. Different compressive damage parameters are considered based on the given equivalent plastic strains.

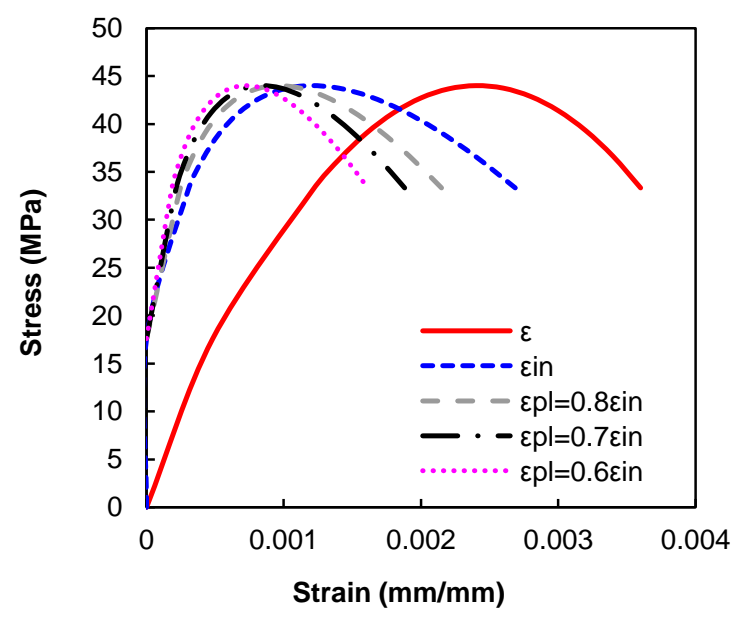

Figure 7: Compressive stress-strain curves for slab SB1. 


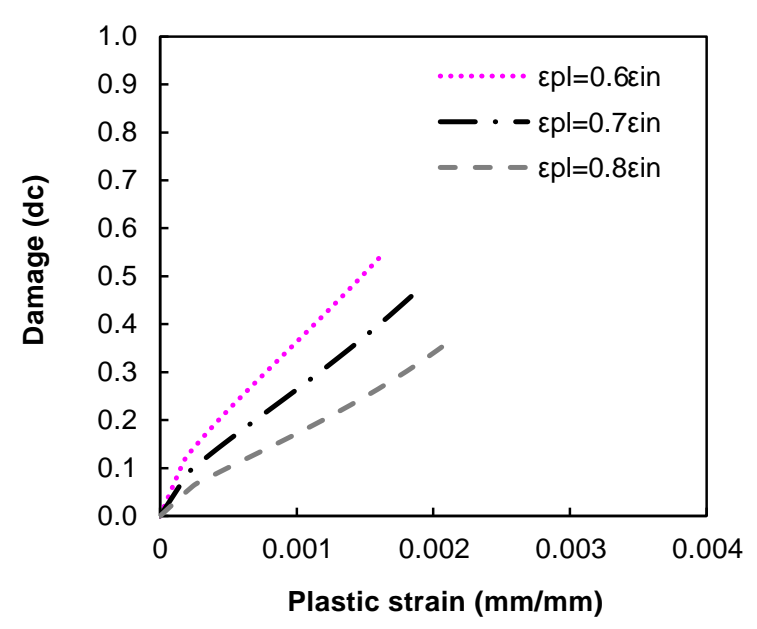

Figure 8: Compressive damage-plastic strain curves for slab SB1.

\subsection{Modelling methodology}

One quarter of the real slab-column connections is modelled in ABAQUS due to symmetry. Concrete is modelled with $3 \mathrm{D}$ 8noded hexahedral elements with reduced integration (C3D8R) and the flexural reinforcement is modelled with $3 \mathrm{D}$ 2-noded linear truss elements (T3D2). Perfect bond is considered between concrete and reinforcement through the embedded method in ABAQUS. The mesh size is considered equal to $20 \mathrm{~mm}$ based on a previous research [2]. The shear bolts are modelled with 3D solid elements, where $9.5 \mathrm{~mm}$ diameter is used for the bolts' stud, $30 \mathrm{~mm}$ diameter for the heads and $44 \mathrm{~mm}$ diameter for the $10 \mathrm{~mm}$ thick washers according to the real test. The bolts are installed into the $16 \mathrm{~mm}$ drilled holes of the slab. Tie constraints are adopted to model the interaction between the washers of the bolt and the slab surface. Tie constraints tie two separate surfaces together in order no relative motion between them to exist. The advantage of this type of constraint is that allows the two regions to be fused together even if their meshes are not similar. Very important is the proper mesh of the slab due to the present of holes. For that reason the mesh is created after the proper partition of the slab. Figure 9 illustrates the shear bolt modelling and the mesh configuration of the bolt and the surrounding area on the slab.

Static analysis under displacement control is conducted in ABAQUS/Standard. Simple supports are introduced along the edges of the slabs at the bottom. Viscoplastic regularization is considered where the viscosity parameter is taken equal to $0.00001[2]$.

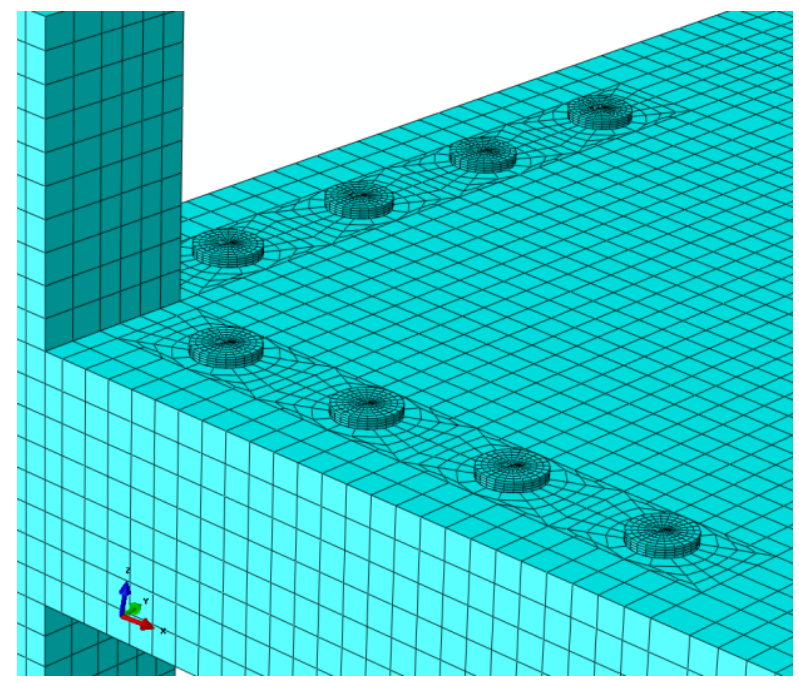

Figure 9: Mesh configuration of SB4.

\section{FINITE ELEMENT ANALYSIS RESULTS}

\subsection{Load-deflection response}

A parametric investigation based on the different options that we can use in order to define the tensile stress-crack displacement relationship is considered for the specimen SB1. During this investigation the value of the fracture energy and the maximum value of the compressive damage parameter are also examined. Figures 10, 11 and 12 show the numerical results of the slab SB1 in terms of load-deflection response for all three tension softening options, where the fracture energy is calculated based on the CEB-FIP Model Code 1990. The analyses in Figure 10 consider the plastic strain $\left(\varepsilon^{p l}\right)$ equal to $0.8 \varepsilon^{i n}$, while in Figures 11 and 12 the plastic strain is equal to $0.7 \varepsilon^{i n}$ and $0.6 \varepsilon^{\text {in }}$, respectively. This relationship between the plastic and the inelastic strains implies the values for the compressive damage variables. Figure 13 illustrates the load-deflection responses of the slab SB1 again for all three different tension softening options, however in these analyses the fracture energy is calculated using the formula from the CEB-FIP Model Code 2010. 
The plastic strain is considered equal to 0.6 times the inelastic strain.

In all the analyses, the linear tension softening response underestimates the punching shear capacity of the slab. When the plastic strain $\left(\varepsilon^{p l}\right)$ is equal to $0.8 \varepsilon^{\text {in }}$ the bilinear approach overestimates the load capacity of the slab, while the exponential tension softening approach predicts accurately the load-deflection response of the slab. If we consider now the numerical results of Figure 11, where the compressive damage is increased, again the linear tension softening response underestimates the load capacity of the slab. However, both the bilinear and exponential tension softening approaches capture in a good way the test load-deflection response of the slab. If we increase more the compressive damage (Figure 12), again the linear tension softening response underestimates the load capacity of the slab. However, the bilinear tension softening approach is in good agreement with the test load-deflection response of the slab. The exponential tension softening response seems to underestimate the punching shear capacity of the slab as the damage that is introduced in the model is activated earlier compared to the two other tension softening approaches.

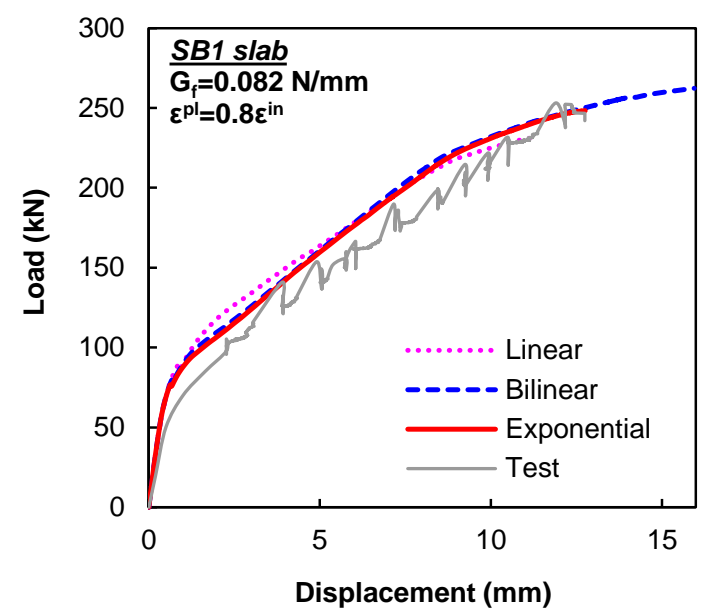

Figure 10: Load-deflection response of slab SB1 $\left(\mathrm{G}_{\mathrm{f}}=0.082 \mathrm{~N} / \mathrm{mm}\right.$ and $\left.\varepsilon^{\mathrm{pl}}=0.8 \varepsilon^{\mathrm{in}}\right)$.

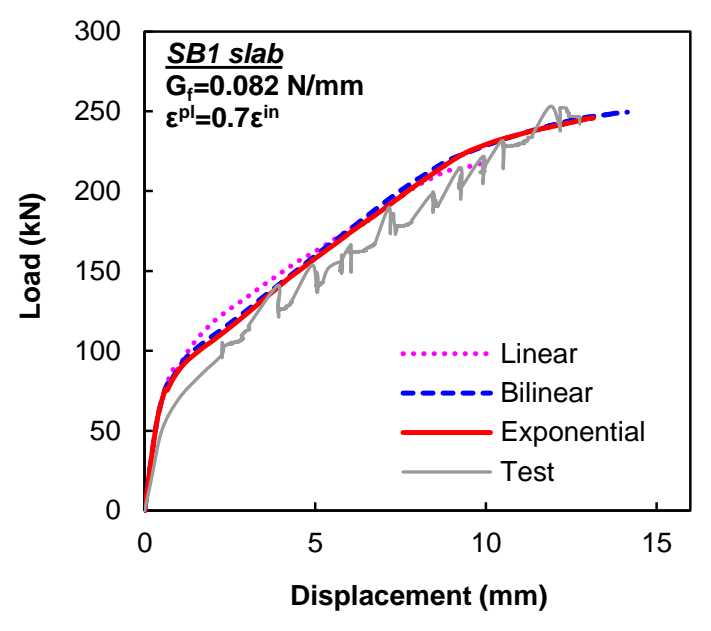

Figure 11: Load-deflection response of slab SB1 $\left(\mathrm{G}_{\mathrm{f}}=0.082 \mathrm{~N} / \mathrm{mm}\right.$ and $\left.\varepsilon^{\mathrm{pl}}=0.7 \varepsilon^{\mathrm{in}}\right)$.

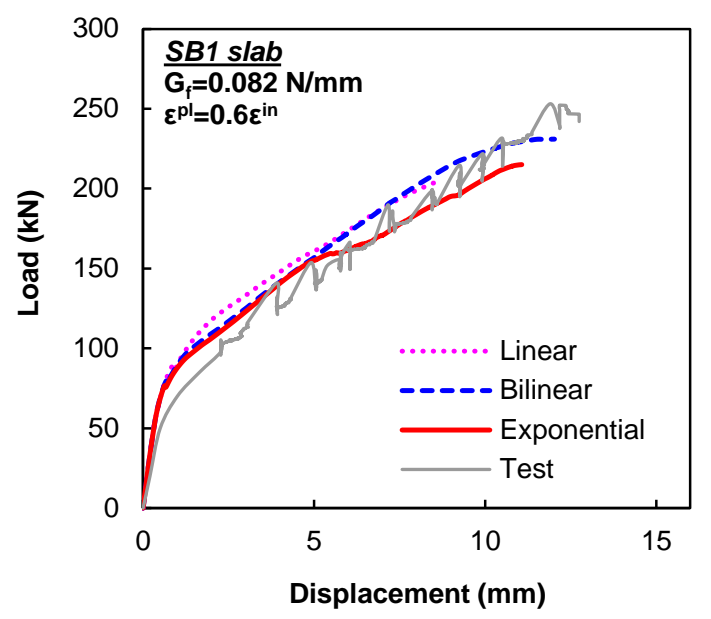

Figure 12: Load-deflection response of slab SB1 $\left(\mathrm{G}_{\mathrm{f}}=0.082 \mathrm{~N} / \mathrm{mm}\right.$ and $\left.\varepsilon^{\mathrm{pl}}=0.6 \varepsilon^{\mathrm{in}}\right)$.

When the fracture energy is considered higher (Figure 13) all tension softening approaches give a stiffer response for the slab and the exponential response fails to simulate the load-deflection response of the tested slab. 


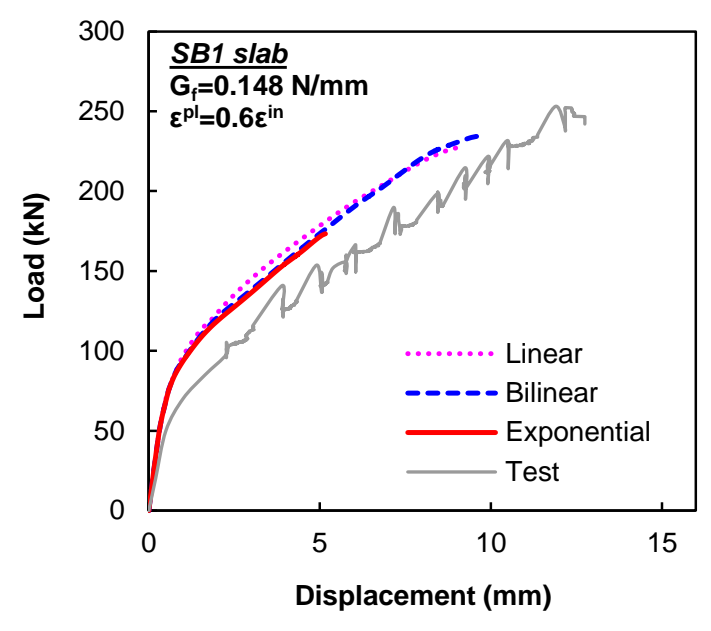

Figure 13: Load-deflection response of slab SB1 $\left(\mathrm{G}_{\mathrm{f}}=0.148 \mathrm{~N} / \mathrm{mm}\right.$ and $\left.\varepsilon^{\mathrm{pl}}=0.6 \varepsilon^{\mathrm{in}}\right)$.

Considering now the numerical results presented in the previous graphs for the slab SB1 we can state that the fracture energy calculated according to the CEB-FIP Model Code 1990 presents accurately the loaddeflection response of the slab. If we compare now the three different tension softening approaches we can see that both the bilinear and the exponential responses are in good agreement with the test results. Regarding the relationship between the plastic and inelastic strains that describes the compressive damage variables, the relationship $\varepsilon^{p l}=0.7 \varepsilon^{\text {in }}$ for both exponential and bilinear responses gives accurate prediction and it is in good agreement with the test results. Thus, for the analysis of the slab SB4 presented below the exponential tension softening approach is chosen to be used together with the fracture energy calculated using the CEB-FIP Model Code 1990.

The failure load in FEA of the SB4 is 342 $\mathrm{kN}$ and the displacement at such load is 31 $\mathrm{mm}$. These numerical results are in good agreement with the test results. Figure 14 shows that when the displacement started to be imposed at the top of the column at the beginning of the FEA and until a load of 250 $\mathrm{kN}$, the load-deflection response of the slab is in an excellent agreement with test response. At this load $(250 \mathrm{kN})$ the shear bolts started to be activated in the real test. In the FEA the shear bolts started to be activated at this load, however not in the same way as happened in the real test and this is the reason that the loaddeflection response shows a difference.

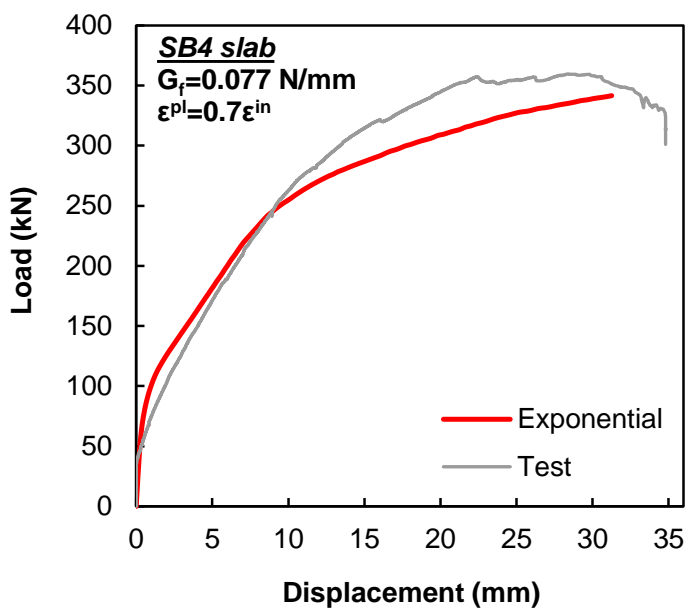

Figure 14: Load-deflection response of slab SB4 (Exponential tension softening response).

\subsection{Cracking propagation}

The cracking propagation for both slabs at failure is presented below. The cracking on the tension side of the slab SB1 at failure is presented in Figure 15. The cracking propagates inside the slab adjacent to the column and then it extends radially as the load increases. At the failure the punching shear cone is visible due to the sudden opening of the cracks.

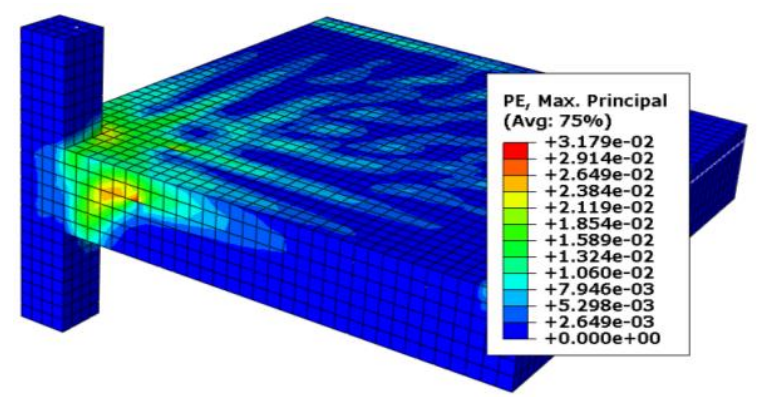

Figure 15: Maximum principal plastic strains of slab SB1 (cracking at ultimate load).

Specimen SB4 failed in flexure first and then it experienced shear cracks outside the shear reinforcement area and bending cracks around the column. The bending cracks at the face of the column seem to be greater compared to the bending cracks that specimen SB1 appears. Also, outside the shear reinforcement it can be seen the shear crack. A second post-failure shear crack can be viewed 
between the two first rows of the shear bolts.

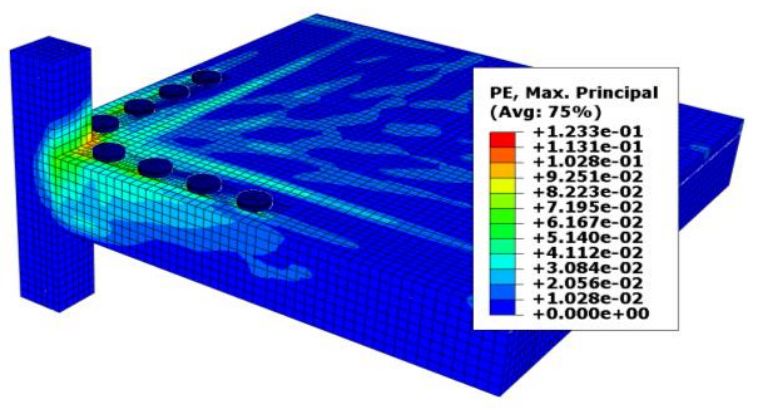

Figure 16: Maximum principal plastic strains of slab SB4 (cracking at ultimate load).

\section{CONCLUSIONS}

The paper presents the concrete modelling in both tension and compression for punching shear simulations using the concrete damaged plasticity model in ABAQUS. A proper investigation is performed regarding the values of the damage parameters that can be considered in both tension and compression. The parametric investigation is conducted by analyzing the slab SB1. The values of the fracture energy and the tension stiffening response are also under investigation.

The calculated fracture energy according to the old CEB-FIP Model Code 1990 seems to simulate in a better manner the load-deflection response of the slab SB1, compared to the new CEB-FIP Model Code 2010. Higher value of the fracture energy makes the loaddisplacement response of the slab stiffer, resulting the slab to fail in a lower deflection. Now, for the most appropriate given values of the compressive damage variables it seems that they come if we consider the plastic strains equal to 0.7 times the inelastic strains. The exponential and the bilinear tension softening approaches present better results in terms of load-deflection response compared to the results that the linear tension softening approach shows. Thus, a proper modelling material investigation should be performed prior to FEA. This calibrated material model is compared to the test results, and then it can be used for the numerical analyses and further parametric studies.

The numerical results for both slabs are in good agreement with the test results in terms of load-deflection response and cracking propagation. A further investigation will be conducted for the specimen SB4, where other modelling approaches will also be examined for the simulation of the shear bolts.

\section{REFERENCES}

[1] Ožbolt, J., Vocke, H., and Eligenhausen, R. 2000. Three-dimensional numerical analysis of punching failure. Proc. of the international workshop on punching shear capacity of RC slabs, Royal Institute of Technology, Department of Structural Engineering, Stockholm, 65-74.

[2] Genikomsou, A.S., and Polak, M.A. 2015. Finite element analysis of punching shear of concrete slabs using damaged plasticity model in ABAQUS. Engineering Structures 98:38-48.

[3] ABAQUS Analysis user's manual 6.12-3 2012. Dassault Systems Simulia Corp, Providence, RI, USA.

[4] Adetifa, B., and Polak, M.A. 2005. Retrofit of interior slab-column connections for punching using shear bolts. ACI Structural Journal 102:268-274.

[5] Lee, J. and Fenves, G.L. 1998. Plasticdamage model for cyclic loading of concrete structures. ASCE Journal of Engineering Mechanics 124:892-900.

[6] Cornelissen, H., Hordijk, D., and Reinhardt, H. 1986. Experimental determination of crack softening characteristics of normal weight and lightweight concrete. Heron 31:45-56.

[7] Comité Euro-International du Béton, CEB-FIP-model Code 1990: Design code, Thomas Telford, London, 1993.

[8] Comité Euro-International du Béton, CEB-FIP-model Code 2010. Lausanne, Switzerland, 2010. 